\title{
LA LEY NATURAL EN FRANCISCO DE SUÁREZ: EXALTACIÓN DE LA LIBERTAD*
}

\author{
MANUEL LÓPEZ CASQUETE DE PRADO \\ Universidad Loyola Andalucía
}

\begin{abstract}
RESUMEN: La formulación suareciana sobre la ley natural ofrece una de las elaboraciones más brillantes y acabadas de la tradición iusnaturalista. En este artículo analizamos las claves desde las que Suárez formula su propuesta, la cual encuentra en el concepto de libertad su punto culminante. Desde la llamada radical e irrenunciable del ser humano al ejercicio de su libertad, Suárez desgrana lo esencial de su elaboración, una de cuyas derivas terminaría por decantar - siglos después - el concepto de derecho subjetivo. Así mismo, hacemos especial mención de los aspectos epistemológicos de su sistema, que consideramos esenciales para abordar una correcta comprensión de la propuesta iusnaturalista suareciana. Para ello ofrecemos una ceñida comparación con la gnoseología tomista de la ley natural.
\end{abstract}

PALABRAS CLAVE: Ley natural; Suárez; epistemología; tomista; libertad; illatio.

\section{Natural Law in Francisco Suárez: Passion for Freedom}

ABSTRACT: The Suaretian formulation on the natural law offers one of the most brilliant and accomplished elaborations of the ius-naturalistic tradition. In this article we analyze the keys from which Suárez formulates his proposal, that finds in the concept of freedom its starting point. From the radical and inalienable call to the human being to the exercise of his freedom, Suárez reveals the essence of its elaboration, one of whose consequences would end by decanting -later on - the concept of subjective right. We also pay special attention to the epistemological aspects of its system, which we consider essential to approach a correct understanding of the Suaretian ius-naturalistic proposal. For this purpose, we offer a close comparison between the Suaretian system and the Thomistic epistemology of the natural law.

KEY WORDS: Natural law; Suarez; epistemology; thomistic; freedom; illatio.

\section{INTRODUCCIÓN: LA LIBERTAD COMO FUNDAMENTO}

La reflexión iusnaturalista contenida en la obra de Francisco de Suárez SJ merece ser objeto de estudio pormenorizado por su carácter complejo e innovador:

Con él se inició la Edad Moderna con un vigor incluso superior al de las obras de Grocio y de Pufendorf. Poseyó un muy fuerte prestigio mundial hasta entrada la Edad Contemporánea ${ }^{1}$.

Algunos autores incluso sitúan la teoría iusnaturalista de Suárez como la más importante de la Historia de la Filosofía. Este es el caso de William May

Este artículo se enmarca dentro del Proyecto I+D+I «Pensamiento y tradición jesuita y su influencia en la Modernidad desde las perspectivas de la Historia, la Traductología y la Filosofía Jurídica, Moral y Política» (PEMOSJ), financiado por el Ministerio de Economía y Competitividad del Gobierno de España y el Fondo Europeo de Desarrollo Regional (MINECO/FEDER) (referencia FFI2015-64451-R), y cuyo investigador principal es el Prof. Dr. Juan Antonio Senent de Frutos.

1 Contreras (2014), p. 97. 
(recientemente fallecido), una de las voces más autorizadas a nivel internacional en la defensa de la recuperación del concepto de la ley natural:

A lo largo de la historia de la Filosofía y Teología moral han sido propuestas diferentes teorías acerca de la ley natural. Entre esas, la más extensa, importante e influyente es la del escolástico renacentista Francisco Suárez (1548-1617). Su sólido De legibus ac de Deo Legislatore es un trabajo impresionante, notable por su vasta erudición, profundidad y alcance, lógica e internamente consistente. El trabajo de Suárez, además, ha ejercido considerable influencia sobre posteriores teóricos de la ley natural, particularmente dentro de la tradición Católica romana² .

La reflexión iusnaturalista de Suárez está contenida en la Defensio Fidei, obra extensa y sistemática encargada por el Papa para rebatir la doctrina inglesa sobre el origen divino del poder real, y — sobre todo- en el libro II del De legibus ${ }^{3}$. Este libro II está dividido en 20 capítulos, dedicados al estudio de la ley eterna (1 a 3), la ley natural (4 a 16) y el derecho de gentes - que, por su cercanía con la ley moral natural, se incluye también en este libro II-(17 a 20).

\subsection{Derecho natural concesivo: en la antesala de los derechos subjetivos}

El problema de la ley natural es enfocado por Suárez desde la reflexión sobre la libertad, concepto central y clave de bóveda de su propuesta iusnaturalista. Es justamente la libertad —en la comprensión suareciana— la que otorga al hombre su dignidad, su identidad de imago Dei, y la que le habilita como sui iuris o criatura capaz de autogobierno ${ }^{4}$. De ahí deriva una de las más brillantes contribuciones de Suárez: la distinción entre derecho natural imperativo (que ordena de forma taxativa la necesariedad y obligatoriedad de un determinado comportamiento - p.e.: no matarás-) y derecho natural concesivo, caracterizado como la libertad natural que corresponde a cada ser humano por estar creado a imagen y semejanza de Dios ${ }^{5}$.

Suárez se refiere a la libertad como derecho intrínseco del hombre, lo que significa que el hombre no puede estar poseído, esclavizado o dominado por el poder de ningún otro hombre, sino que tiene el control sobre sus facultades, acciones y miembros, y esto por designio creador de Dios ${ }^{6}$. En conjunto, a la facultad de ejercicio de esta libertad, Suárez la llama «el mayor de los derechos» ${ }^{7}$.

2 MAY (1984), p. 409.

3 Todas las citas del De legibus contenidas en este trabajo han sido tomadas de la versión del Consejo Superior de Investigaciones Científicas, instituto Francisco de Vitoria, Madrid, 1971 y ss.

4 BRust (2012), p. 348.

5 Contreras (2014), p. 98.

6 De Legibus, libro 2, cap. 14, $\mathrm{n}^{\circ}$ 16, 141.

7 Defensio fidei, libro 6, cap. 4, no 5: Quia ius tuendae vitae est maximus. 
Según algunos autores ${ }^{8}$, a Suárez le sobra la ley natural, dado que su búsqueda se orienta hacia una libertad originaria anterior a la propia ley natural (la qualitas moralis). Esto supone una auténtica novedad, y permitió a Suárez defender la existencia de derechos subjetivos de libertad, que él aplica a las formas de gobierno, a la libertad de conciencia y a los derechos privados ${ }^{9}$. En su argumentación, paralela a la de Molina, afirma que la persona tiene derecho a comer su comida y vestir su vestido. De este modo, y desde el ámbito de las objetividades metafísicas de la ley natural, nace un haz de derechos privados para los propietarios, arrendatarios, usufructuarios... ${ }^{10}$. El alcance de este planteamiento es decisivo, ya que toma en consideración una gran cantidad de actuaciones humanas que no están de suyo permitidas ni prohibidas por la ley natural. ¿Qué hacer en esos caso? ¿Le es lícito al ser humano actuar de un modo no previsto por los preceptos inmutables de la ley natural? La respuesta de Suárez, contenida en el libro II del Tractatus, apunta a la existencia de un derecho natural concesivo que ampara una amplia variedad de comportamientos permitidos por la ley natural sin ordenarlos. Dicho con otras palabras, la razón natural no sólo fundamenta lo que es necesario, sino también posibilita lo que no es ilícito.

De este planteamiento se abre la tradición jurídica de los derechos subjetivos, que Suárez establece —aunque bajo otra expresión — al distinguir dos acepciones del término ius:

- Por una parte alude a una facultad o derecho que asiste a una persona.

- Por otra, atiende al precepto legal que establece una regulación general.

Al primer sentido de la palabra ius, Suárez le llama ius utile o ius reale, antecedente directo del concepto de derecho subjetivo (natural, en este caso) ${ }^{11}$.

Este concepto — que podríamos denominar sintéticamente como derecho subjetivo natural - exige de los demás (incluso de las autoridades políticas y civiles) abstenerse de imponer cualquier límite a quien actúa en el marco de lo permitido por la ley natural. Se trataría de una libertad originaria que consagra nuestro derecho a obrar (ius facti), que es de naturaleza divina y que remite al carácter originario y absoluto de las libertades, que no dependen de una ley anterior $^{12}$, sino a una facultad conferida por Dios mismo al ser humano e inserta en su propia naturaleza por voluntad del Creador.

\subsection{El derecho natural en equilibrio: lo concesivo y lo imperativo}

Cabría pensar que, llevando hasta el final este planteamiento, Suárez estaría entronizando el libre albedrío como primer mandato de la ley natural y principal

\footnotetext{
8 Contreras (2014), p. 98.

9 De Legibus, libro 1, cap. 2, no 5.

10 Carpintero (2008), p. 190.

11 Como es bien sabido, el concepto de derecho subjetivo no se generalizó hasta el siglo XVIII. Hasta entonces, se utilizaba el suareciano ius utile.

12 Carpintero (2008), p. 199.
} 
guía de actuación ética. Sin embargo, el ejercicio de esta libertad se enmarca en el sistema suareciano dentro del entramado de obligaciones propias de las relaciones comunitarias, las leyes y las distintas instancias normativas: divina, natural, canónica y civil, y que entroncan con el otro marco normativo de la ley natural: su versión imperativa. Es justamente este contexto normativo el que concreta desde las formulaciones más generales hasta las más detalladas los preceptos que derivan de la ley natural ${ }^{13}$. En la parte más baja de esta jerarquía, Suárez sitúa la ley positiva, cuya imperatividad enraíza en quién promulga la norma, y no tanto en la necesariedad de su contenido. Desde esta comprensión, Suárez afirma que la libertad es la facultad para hacer lo que se desee siempre que no haya sido prohibido por la ley (en sus distintas instancias normativas) ${ }^{14}$. Ambas versiones de la ley natural — concesiva e imperativa- establecen el equilibrio en el sistema iusnaturalista suareciano.

Para Suárez, en continuación con el argumento anterior, la dignidad del hombre y su carácter de imago Dei hacen que sólo a Dios deba servidumbre, y no a príncipes o potestades humanas. De ahí su defensa de la democracia como forma de gobierno más cercana a la ley natural. La democracia, por tanto, sería el sistema de organización política que mejor sirve para contextualizar el juego entre los dos ámbitos mencionados del derecho natural: el concesivo y el imperativo. La razón de este planteamiento es que, según el autor, la democracia no requiere de ninguna institución positiva entre los ciudadanos y el gobernante, sino que es la concreción política natural de la libertad humana (ex sola naturali institutione):

Democratiam ese ex divina institutione, respondemus, si hoc intelligatur de institutione positiva, negandam ese consecutionem: si vero intelligatur de institutione queasi naturali, sine ullo inconveniente admitti posse, et debere ${ }^{15}$.

Este tema es tratado de forma pormenorizada en la Defensio Fidei, donde sostiene que el príncipe no ostenta su cargo por derecho natural ni por derecho divino $^{16}$. La principal deriva política de la ley natural en el sistema suareciano es la igual libertad de todos los ciudadanos, de forma que el poder político existe únicamente en el pueblo unido ${ }^{17}$. El pueblo unido es, por tanto, el depositario del poder que emana de Dios, el cual convierte a los hombres en sui iuris, como ya había indicado Tomás de Aquino. Por tanto, si la libertad del hombre es presupuesto de derecho divino, nadie puede perder su libertad salvo por su propio consentimiento. De este modo, sólo sería legítima una forma de gobierno distinta a la democrática si el pueblo así lo determinase (con lo que, en última

\footnotetext{
13 BRust (2012), p. 350.

14 Tractatus Secundus, libro 1, cap. 3, n 13.

15 SuÁrez, 1613, L. III, cap. 1, nº 8.

16 Recordemos que, como ya se ha dicho, esta obra es escrita para combatir la pretensión inglesa de sostener la designación divina de los reyes, lo cual es de gran relevancia a este respecto.

17 Carpintero (2008), p. 207.
} 
instancia, la garantía democrática quedaría siempre a salvo, aunque fuera para que el pueblo determinase un modo distinto de organización política, y en tanto esa decisión no fuera revocada).

Junto a Molina, y en paralelo a Santo Tomás, Suárez sostenía que el ser humano tiene dos fines últimos, uno de orden natural - del cual se ocupa el poder político-y otro de orden sobrenatural — del que se ocupa la Iglesia-. Se abunda así en la línea de separación y autonomía de los dos poderes, lo cual en pleno siglo XVII supone una apuesta decidida por superar las guerras religiosas.

\section{Epistemología de la ley natural: Santo Tomás y SuÁrez a debate}

\subsection{La naturaleza inmutable de las cosas}

La inmutabilidad de la ley natural es uno de los principales escollos especulativos a los que la tradición iusnaturalista ha tenido que hacer frente. Existe un amplio consenso entre los iusnaturalistas en que los preceptos contenidos en la ley natural apuntan a lo que es bueno o malo per se $e^{18}$. Ese es el planteamiento recogido también por Tomás de Aquino en la Summa theologica:

El derecho natural nace con la criatura racional; y no cambia con el tiempo, sino que permanece inmutable ${ }^{19}$.

Francisco de Suárez lleva el argumento de la inmutabilidad de la ley natural hasta el extremo. Aunque es posible hallar en Suárez planteamientos que apuntan a que la naturaleza racional es creación contingente de Dios, ya que sólo Dios es necesario, en el De legibus plantea de forma clara que la ley natural es inmutable incluso para $\operatorname{Dios}^{20}$. Este carácter inmutable de la ley natural se basa, según Suárez, en un doble argumento: primero por parte de la mente en la que está escrita (la divina), que no puede contradecirse a sí misma; segundo, por la propia naturaleza de las conductas que regula, ya que prohíbe lo que es intrínsecamente malo y ordena lo que es intrínsecamente bueno y necesario por sí, y por tanto inmutable. Esto no implica en el sistema suareciano que Dios esté sometido a la ley natural, dado que todo precepto es la orden de un superior, y Dios no conoce superior ${ }^{21}$. Es la voluntad divina la que da lugar a la ley natural, que es consecuencia — por tanto- de un acto libre de Dios ${ }^{22}$.

Este planteamiento introduce un matiz propio y muy significativo en Suárez en lo que se refiere a epistemología de la ley natural, ya que anula toda

\footnotetext{
18 Williams (1998), p. 97.

19 Summa theologica, I-II, q. 94, art. 5.

20 CARPintero (2008), p. 193.
}

21 La cuestión del sometimiento o no de Dios a la ley natural es un asunto especulativo delicado. Según Suárez, Dios no puede estar sometido a la ley natural, dado que todo precepto es la orden de un superior, y Dios no conoce superior. La ley natural se aplica, por tanto, solamente a las criaturas de Dios. Este asunto es ampliamente tratado en el De legibus, vol. III, 1974, pág. 2. Sobre ello, Baciero (2007), p. 106.

22 BACIERO (2007), p. 108. 
posibilidad de subjetivismo en su conocimiento e interpretación al reclamar la necesariedad y evidencia de sus preceptos. Aunque tanto Aquino como Suárez parten de la inmutabilidad de la ley natural, la diferencia de planteamiento genera también un fuerte contraste epistemológico en ambos: si Suárez enfatiza que los principios de la ley natural son evidentes y necesarios por sí mismos (aunque de formas distintas según el grado de concreción de cada principio, como veremos), Santo Tomás contempla una epistemología más abierta de la ley natural en la que la inclinación juega un papel determinante. Es decir, en el sistema tomista, las cosas revelan al ser humano un fin último que siente como suyo, ya que las conductas rectas le son apetecibles y le conducen al fin propio y natural de encontrarse con Dios. Suárez, por el contrario, se mantiene firme en el ámbito de la mera racionalidad, capaz de acceder a unos preceptos inmutables y necesarios. Conviene que nos detengamos en ese punto para revisarlo con mayor detalle.

\subsection{Epistemología tomista de la ley natural: la primacía de la inclinación}

Según la tradición tomista, y desde el punto de de vista gnoseológico, el fundamento de la ley natural deriva de la sabiduría creadora de Dios. Sin embargo, no es necesario creer en Dios para conocerla y respetarla: basta con conocer la naturaleza humana. Con otras palabras, el conocimiento de la ley natural no deriva de la fe, ni siquiera de la razón, sino fundamentalmente de la inclinación de nuestra naturaleza, lo cual marca un camino oscuro y asistemático. En palabras de V. Possenti, dicho conocimiento por inclinación

Non è una conoscenza chiara per concetti e giudizi concettuali; è una conoscenza oscura, non-sistematica, vitale, che procede per esperienza tendenziale o per "connaturalità» e nella quale l'intelletto per formare un giudizio consulta e ascolta quella specie di canto prodotto nel soggetto dalla vibrazione delle sue tendenze interiori ${ }^{23}$.

Por este motivo, el conocimiento de la ley natural ha ido avanzando con la historia y continúa desarrollándose como fruto de la evolución y el progreso humano. De ahí que la captación que hace cada cultura y cada época de la ley natural sea también distinta:

Thus, natural law does not change because human nature does not change. What changes is knowledge of human nature - for better or for worse $-{ }^{24}$.

De este planteamiento gnoseológico se derivan importantes consecuencias: puesto que la ley natural no deriva de la fe, sino de la inclinación común de nuestra naturaleza humana, puede ser conocida y compartida por todos los seres humanos. En palabras de Viotto, sobre la base del reconocimiento

23 Possenti (2003), p. 138.

24 DenNey. 
práctico de esta ley natural, aun partiendo de diversas motivaciones teóricas, se puede articular un diálogo que supere tanto el relativismo como el fundamentalismo ${ }^{25}$.

Para McCauliff, esta inclinación es preconceptual. Un preconcepto es un concepto no formulado ni verbalizado; sobre dicha intuición, la comprensión humana debe realizar un proceso de actualización mediante el racionamiento discursivo, la investigación, el análisis, la elaboración de teorías y la verificación. De este modo, los preceptos de la ley natural son cognoscibles inmediatamente por inclinación, pero no pueden ser demostrados porque para ello precisan de la razón, que proporciona un conocimiento mediato ${ }^{26}$.

Aunque algunos autores han matizado el peso que Santo Tomás otorga a la inclinación como vía epistemológica principal de la ley natural ${ }^{27}$, nos parece evidente la importancia decisiva que le otorga el sistema tomista. Así, en la Suma teológica:

Hay en el hombre una inclinación al bien correspondiente a la naturaleza racional, que es la suya propia, como es, por ejemplo, la inclinación natural a buscar la verdad acerca de Dios y a vivir en sociedad ${ }^{28}$.

Esta inclinatio ad bonum nos parece central en la gnoseología tomista de la ley natural, ya que el propio Santo Tomás la considera íntimamente esencial al ser humano (quae est sibi propria); tal centralidad ostenta en el sistema tomista, que es comparada con la propia inclinación de la persona al conocimiento de Dios. Así lo entiende también Wechsung, que cita a este respecto la Summa contra gentiles: Todo está ordenado a un solo fin que es Dios ${ }^{29}$.

Wechsung interpreta esta cita desde la idea de que en todos los entes creados hay una inclinación por la cual se dirigen de modo necesario al fin conveniente según la propia naturaleza. En consecuencia, las cosas creadas están gobernadas por Dios mediante las inclinaciones naturales, y asi se someten al orden de la ley eterna ${ }^{30}$. Y en otro lugar: a la ley natural pertenecen las cosas a las que el hombre se inclina según su naturaleza ${ }^{31}$.

Aún más clara nos parece a este respecto la siguiente cita de la Suma teológica, que no deja lugar a ninguna duda:

Por lo mismo, hay también en ella [la criatura racional] una participación de la razón eterna en virtud de la cual se encuentra naturalmente inclinada a los actos y fines debidos. Y esta participación de la ley eterna en la criatura racional es lo que se llama ley natural ${ }^{32}$.

\footnotetext{
25 Viотто (2010), p. 30.

26 McCauliff (2009), p. 445.

27 Burgos (2006), pp. 116-117.

28 Summa theologica (2001), tomo II, p. 733.

29 Suma contra gentiles, libro 3, cap. 16.

30 Wechsung (2003), p. 4.

31 Wechsung (2003), p. 9.

32 Summa theologica, tomo II, p. 736.
} 
Ciertamente, en Santo Tomás la inclinación natural no es una vía cognoscitiva separada de la razón y de la voluntad, sino que se articula y armoniza con ella en forma de una inclinación racional como participación humana en la razón creadora (del mismo modo que en el orden práctico la inclinación se armoniza con la voluntad). Sin embargo, a pesar de esto, parece claro el lugar de primacía lógica y cronológica que Santo Tomás atribuye a la inclinación sobre la elaboración racional.

Esta orientación gnoseológica es la misma que plantea la Comisión Teológica Internacional al conceptuar la ley natural:

El concepto de ley natural supone la idea de que la naturaleza es portadora de un mensaje ético que se constituye en norma moral cuando la razón humana lo actualiza ${ }^{33}$.

En cualquier caso, la centralidad de la inclinación nos parece absolutamente incuestionable en el planteamiento gnoseológico tomista de la ley natural. En dicho planteamiento ${ }^{34}$ se produce una primera captación por inclinación de la ley natural de la que derivan preceptos primarios de contenido muy general (los relativos a la conservación de la vida, la reproducción y el impulso al conocimiento de la verdad). De estos preceptos, y por obra de la razón discursiva, la persona puede acceder a preceptos secundarios de contenido más específico $^{35}$. Como el propio Aquino especifica, a medida que se desciende a principios más particulares, aumenta la indeterminación ${ }^{36}$. Este descenso a concreciones particulares es descrito por Jacques Maritain cuando muestra las diferencias entre derecho natural, derecho de gentes y derecho positivo; este autor ilustra con claridad cómo se va incrementando el grado de contingencia y mutabilidad a medida que aumenta el grado de concreción. Del mismo modo, y a nivel epistemológico, a medida que se desciende en el grado de concreción es mayor el peso de la elaboración racional-discursiva historizada y menor el de la inclinación ${ }^{37}$. En la misma línea, para Sweet,

It surely is more plausible to hold that such [secundary] precepts are derived from the principles of the natural law by way of inference and, therefore, that they are better understood as part of what he calls the droit des gens or the common law of civilisations ${ }^{38}$.

En conclusión, y en contra del argumento de Burgos, sostenemos que Santo Tomás otorga una clara primacía epistemológica a la inclinación, la cual debe armonizarse posteriormente con las exigencias de la razón para interpretar,

\footnotetext{
33 Comisión teológica internacional (2009), nº 69.

34 Summa theologica, tomo II, pp. 757 y ss.

35 IrRAZÁBAL (2011), p. 15.

36 Summa theologica, tomo II, pp. 760 y ss.

37 En cualquier caso, este planteamiento no está exento de problemas especulativos, en particular en lo referente a la prioridad o jerarquía de los distintos preceptos en el conjunto de la ley natural. Sobre esto, Sweet, 1998.

38 SWEET (1998), p. 147.
} 
dotar de sentido y — sobre todo— concretar la captación intuitiva. Como afirma Irrazábal,

Este conocimiento está mediado, por una parte, por las inclinaciones de la naturaleza, expresión de la sabiduría creadora, y por otra, por la luz de la razón humana, que interpreta y que es ella misma una participación creada en la luz de la inteligencia divina ${ }^{39}$.

Esta epistemología de la ley natural debe resolver el problema del posible subjetivismo derivado de una vía de conocimiento tan personal como la inclinación. Sin embargo, no hay por qué suponer que la inclinación no pueda obedecer a un mismo impulso natural humano, y que las captaciones que ofrece no pudieran ser compartidas por todos los hombres (p.e., en la regla de oro tomista: hacer el bien y evitar el mal). Con otras palabras, no está claro que la inclinación excluya la universalidad. En cualquier caso, no ignoramos que se trata de un problema complejo; en palabras de Sweet, reivindicar como ley natural aquello a lo que uno se siente inclinado, posibilita la incursión en un peligroso intuicionismo moral:

Claiming that one can know whether a new inclination is natural, simply by determining whether knowledge of it is obtained connaturally, comes dangerously close to moral intuitionism ${ }^{40}$.

\subsection{Epistemología suareciana de la ley natural: la primacía de la razón}

El contraste entre la epistemología tomista que acabamos de exponer y la suareciana resulta evidente. Como decíamos anteriormente, los preceptos de la ley natural son considerados por Suárez como necesarios, evidentes e inmutables. En paralelo a Gabriel Vázquez y Molina, defendió que la ley natural no puede cambiar mientras permanezca la naturaleza racional con el uso de la razón y de la libertad, ya que la ley natural es una propiedad intrínsecamente necesaria que fluye desde la naturaleza racional ${ }^{41}$.

En este punto, el planteamiento de Suárez parece ser más dogmático que argumentativo, y se limita a indicar autoritariamente que los principios de la ley natural son inmutables (de verdad perpetua) porque son evidentes y necesarios por sí mismos. Para entender esto, es preciso advertir que el planteamiento suareciano se incardina en la tradición que plantea que todo problema jurídico tiene una y sólo una solución justa ${ }^{42}$. En lo que respecta a la ley natural, un mismo acto no puede ser al mismo tiempo consonante y disonante con la ley natural.

La justificación racional de este objetivismo metafísico parece difícil. Suárez, en línea con Molina - y, en última instancia, con un argumento de corte platónico-, parece apuntar a la existencia de un mundo de esencias

\footnotetext{
39 IrRAZÁBAL (2011), p. 18.

40 SWEET (1998), p. 148.

41 CARpintero (2008), p. 194.

42 Esta idea influiría fuertemente en los autores románticos alemanes.
} 
morales objetivas que establecen inequívoca e intemporalmente lo que es justo ${ }^{43}$.

A pesar de lo cuestionable de este argumento, se convirtió en doctrina dominante en la comprensión de la ley natural, especialmente durante la modernidad, en la que los creyentes hallaban la garantía de la fe en la existencia de un mundo metafísico inmutable, y en nombre de tal noúmeno se opusieron al nominalismo ${ }^{44}$.

En suma, Suárez consagra una epistemología pura y exclusivamente racional, donde la necesariedad de los preceptos de la ley natural se impone de forma evidente a la comprensión humana.

¿A qué consecuencias conduce esta inmutabilidad de la ley natural, que en Suárez ofrece perfiles propios y muy distintos a los planteados por Santo Tomás? En el epígrafe anterior veíamos cómo, en el sistema tomista, a medida que se desciende en lo pormenorizado de las concreciones de la ley natural, el contenido de los diferentes sistemas normativos se vuelve más contingente y está más sujeto a variación en los distintos tiempos y lugares. Sin embargo, en el caso de Suárez, la absoluta inmutabilidad de los preceptos de la ley natural hace que también considere inmutables sus determinaciones más concretas, porque la ley es una regla para las operaciones, y los primeros principios no son verdaderas reglas sino en la medida en que se dirigen a los actos concretos ${ }^{45}$. Por tanto, constituyen derecho natural todas las conductas que derivan de forma evidente de los primeros principios. El requisito, por tanto, para que las determinaciones más concretas sean consideradas por Suárez como ley natural ex propia rei natura es que este nexo (illatio) entre el comportamiento y los primeros principios sea claro. De forma general, la ley natural en el sistema suareciano, manda lo que es honesto, y es por tanto conforme a la naturaleza racional del hombre:

Supponimus ex dictis bonum per se honestum seu ad honestatem necessarium et malum illi contrarium esse materiam huius legis, illud ut praecipiendum, hoc ut vitandum ${ }^{46}$.

Esta illatio parece esencial en la determinación del contenido de la ley natural en Suárez, y puede producirse tanto por sus propios términos como por razonamiento. Es decir, el autor concibe tanto una evidencia clara e inmediata de que un comportamiento es honesto, como un proceso de razonamiento mediato:

Ius naturali complecti omnia preacepta seu principia moralia, quae evidentem habent honestatem necessariam ad rectitudinem morum, ita ut opposita moralem inordinationem seu malitiam evidenter contineant ${ }^{47}$. [...] Illa autem quae evidenter cognoscuntur lumine naturae sive cum discursu sive absque illo cognoscantur, recte dicuntur naturaliter fier ${ }^{48}$.

\footnotetext{
43 CARPintero (2008), p. 195.

44 CARPintero (2008), p. 195.

45 Carpintero (2008), p. 204.

46 De legibus, libro II, 7, 1, pp. 109-110.

47 De legibus, libro II, 7, 4, p. 113.

48 De legibus, libro II, 7, 5, pp. 115-116.
} 
En este punto, Suárez reconoce tres tipos de principios morales ${ }^{49}$ :

- Los primeros principios absolutamente generales.

- Los menos generales pero conocidos en sus propios términos.

- Las conclusiones que derivan de los anteriores de forma evidente a través del razonamiento.

Todos estos principios forman parte de la ley natural en tanto que ordenados por Dios, apuntan a lo que es conveniente para la naturaleza del hombre y le señalan un horizonte de perfección natural. Es de señalar que Suárez identifica (seu) la perfección natural con la felicidad natural humana (naturalem perfectionem seu felicitatem humanae naturae $)^{50}$.

Desde esta caracterización, aún no queda resuelto el problema que genera la inmutabilidad de la ley natural. Para solventarlo, Suárez suaviza la rigidez de su propio planteamiento al introducir la distinción entre ley natural y derechos naturales ${ }^{51}$. Todo lo dicho hasta ahora es aplicable a la ley natural, ya que es a ésta a la que Suárez atribuye el carácter de inmutable; en cambio, los derechos naturales tratan de regular situaciones que son por definición cambiantes. Dado que todo lo creado es finito y corruptible, está sujeto a cambio. Esta es la diferencia entre libertad (entendida como precepto de la ley natural) y derecho civil (que formaría parte de los derechos naturales). Los derechos civiles son concreción del derecho natural a la libertad, pero encarnados e historizados en circunstancias y contextos cambiantes, por lo que pueden ser modulados por las distintas instancias normativas humanas. Esta distinción hace más comparable en este punto el sistema suareciano y el tomista; la función que desempeñan en el sistema tomista los primeros principios inmutables encajarían con la ley natural en Suárez, y los principios secundarios tomistas, cuyo grado de mutabilidad y contingencia es mayor a medida que mayor es también el grado de concreción, encajarían con los derechos naturales suarecianos.

Sin embargo, y a pesar de lo dicho, la primacía de la inclinación (Santo Tomás) o de la razón (Suárez) supone un punto de contraste muy claro entre ambos autores. Suárez continúa entronizando el criterio de la pura racionalidad como vía de acceso epistemológico al contenido de la ley natural. Sin embargo, y en línea con lo anterior, el propio Suárez introduce en los Tratados morales una distinción entre dos modos de utilización de la razón en lo relativo a la captación del la prescripción moral:

Qué son la razón superior e inferior-- Pero digo brevemente que hay que distinguir la razón superior e inferior en la materia moral por distintas reglas y motivos de las acciones humanas. Porque cuando la razón es por reglas eternas y divinas en las cuales se contiene la ley natural, se llama superior y cuando juzga por razones y reglas humanas y temporales, se llama razón

49 De legibus, libro II, 7, 5, pp. 115-116.

50 De legibus, libro II, 7, 7, pp. 117-118.

51 De legibus, libro II, capítulo 14, nº 19, 141. 
inferior: de esta manera se distinguen estas razones como por el objeto for$\mathrm{mal}^{52}$.

Es decir, el ser humano dispone de una capacidad racional superior, que es aquella que puede ser aplicada al conocimiento de las reglas eternas y divinas - que contienen la ley natural - y otra inferior que es la aplicada para juzgar según razonamientos y reglas humanas y temporales.

Y aún desciende otro escalón Suárez al abordar la distinción entre derecho natural y derecho positivo. Desde esta distinción, el derecho natural obliga porque acapara toda justicia o bondad posible, por lo que exige obediencia desde sus propios contenidos. En cambio, la ley positiva es creación humana ordenada por quien ostenta la jurisdicción política y versa sobre temas moralmente indiferentes. Por tanto, exige obediencia no por la necesariedad de sus contenidos, sino por el carácter subjetivo de quien lo ordena: aquel en quien el pueblo ha depositado el ejercicio del poder. En conclusión, en el sistema suareciano, si una norma está ordenada por la fuerza de la razón (ex vi rationis), sólo puede pertenecer o fundamentarse en el derecho natural ${ }^{53}$. De este modo se produce en Suárez una extensión de los preceptos de la ley natural que tiende a minusvalorar el derecho positivo.

En cualquier caso, en la propuesta de Suárez, todo derecho está sostenido en última instancia —a través de la ley natural— por Dios mismo, sea por concesión directa (ley natural), mediata (derechos naturales) o indirecta a través de la comunidad que delega el poder en el gobernante (ley positiva): toda ley en algún sentido tiene su origen en la ley eterna, y de ella recibe su fuerza obligatoria ${ }^{54}$.

Por tanto, en última instancia (y en este punto su propuesta es coincidente con la tomista), Dios es el origen de todo poder espiritual y temporal, y la acción de gobierno de las distintas instancias humanas tienen como misión contextualizar y actualizar el derecho natural. Es decir, la ley eterna lo es por esencia, mientras que las restantes sólo por participación ${ }^{55}$. Por eso, toda instancia normativa está obligada a no modificar o anular ningún derecho sin legitimidad política y sin justa causa respecto al bien común ${ }^{56}$.

Esta conceptualización genera una nueva dificultad: si toda instancia normativa es, en última instancia, ley eterna (aunque sea por participación), podríamos concluir que toda ley humana es en cierto modo divina, lo cual resulta obviamente problemático. A este respecto, Suárez responde que la obligación que impone la ley humana no es "divina» de forma directa o inmediata, sino propiamente "humana» en cuanto pensada y promulgada por hombres, siendo al mismo tiempo un "efecto" de la ley divina, tanto en cuanto a su necesaria

\footnotetext{
52 Tratados Morales, tratado $5^{\circ}$, disputa V, secc. 3, $\mathrm{n}^{\circ} 2$.

53 CARPintero (2008), p. 209.

54 Omnem legem aliquo modo esse a lege aeterna (De legibus II, 4, 4, p. 49).

55 BACIERo (2007), p. 109.

56 BRUST (2012), p. 352.
} 
adecuación a ella, como a su fuerza obligatoria última o radical ${ }^{57}$. Además, la ley eterna sólo puede ser conocida por los hombres en esta vida por medio de la ley positiva, que concreta el contenido normativo de la ley eterna y le da carácter obligatorio, ya que sólo ésta y no la ley eterna puede ser "promulgada» ${ }^{58}$.

En cualquier caso, la cuestión de la inmutabilidad de la ley natural resulta muy compleja y, llevada a sus últimas consecuencias, plantea un serio aprieto a Suárez: si la ley natural es necesaria y objetiva, si ni siquiera Dios podría cambiarla, y si el ser humano está obligado a cumplirla sin requerir mandato divino, ¿qué papel juega Dios en la ley natural?

Obviamente, desde semejante esquema conceptual, Dios «sobra» en la configuración de la ley natural. Este planteamiento ya había sido defendido por Luis de Molina y Gabriel Vázquez ${ }^{59}$, quienes consideraban que la naturaleza humana racional bastaba por sí sola para conferir autoridad a los preceptos de la ley natural, opinión con la que sembraron cierto desconcierto en la doctrina teológica ${ }^{60}$.

Suárez se mantiene en la objetividad de la ley natural, pero rechaza que la razón humana contenga todo el fundamento de la rectitud de los actos humanos, y añade que debemos cumplirla por voluntad divina, ya que Dios nos ha dotado de facultades racionales (que son naturales y necesarias) y además nos ordena atenernos a ellas. La recta razón es entendida por Suárez como signo de la voluntad divina, que es la única que puede ordenar o prohibir acciones ${ }^{61}$. En este sentido se opone a Vázquez y Molina, y retoma la definición de ley de Santo Tomás ${ }^{62}$, particularmente en la expresión ab eo qui curam communitatis, que en el caso de la ley natural remitiría en última instancia a Dios.

En opinión de Baciero ${ }^{63}$, Suárez consigue resolver de forma insuperable la disputada cuestión sobre los dos elementos, racional e imperativo, de la ley, y en concreto, de la ley natural en cuanto promulgada por Dios. Según el propio Baciero, es una contradicción en los términos pretender la auto-nomía moral en sentido propio, dado que toda norma implica una instancia superior que dicta el mandato, y nadie puede ser superior de sí mismo ${ }^{64}$.

57 BACIERO (2007), p. 110.

58 Esto resulta obvio, dado que la «promulgación» es un acto temporal.

59 Esta opinión alcanzó cierta difusión en la primera mitad del siglo XVII; de hecho, es citada por Pascal o por el profesor de Cambridge Nathanael Culverwell. Sobre esto, Baciero (2007), p. 111.

60 Carpintero (2008), p. 200.

61 BACIERO (2007), p. 112.

62 Aquino, T. Summa Theologica, I-II, q. 90 a 4.

63 BACIERO (2007), p. 116.

64 BACIERo plantea cómo, en contraste con el sistema kantiano que proclama el rechazo de toda heteronomía moral, autores como Kierkegaard, Scheler o Herbart señalan la imposibilidad de que el hombre se dé a sí mismo la ley moral sin entronizar su deseo como criterio supremo de actuación (BACIERO, 2007, pp. 216 y 217). 


\section{CONCLUSIONES}

Aunque el planteamiento iusnaturalista contenido en la obra de Francisco de Suárez no está exento de dificultades y aprietos especulativos, el doctor eximio parece darles respuesta con solvencia y solidez.

Su distinción entre derecho natural concesivo e imperativo le permite abordar una formulación equilibrada, donde se presta atención a una amplia variedad de comportamientos — los más cotidianos y, quizás por ello, más desatendidos hasta entonces por la doctrina iusnaturalista- que no resultan directamente ordenados por la ley natural, pero cuyo ejercicio es concreción del precepto central de la ley de Dios: la libertad humana. Desde esa perspectiva, empieza a decantarse el concepto de ius utile, antesala de la categoría de derechos subjetivos, que vería la luz en el siglo XVIII. Ambas versiones de la ley natural, la concesiva y la imperativa, permiten que su formulación sea equilibrada y garante de la libertad como vía de desarrollo, de felicitas, dado que la ley natural no sólo fundamenta lo que es necesario, sino también posibilita lo que no es ilícito. Además, se erige como un auténtico límite a posibles acciones de gobierno invasivas o negadoras de una libertad humana querida por Dios en el acto creador.

Manteniéndose dentro de los marcos de la estricta razón, Suárez plantea que el ser humano - imago Dei, ser libre, sui iuris - está facultado para captar de forma segura los contenidos de la ley natural. El concepto clave aquí es el de illatio, el de «hilazón» entre un comportamiento o precepto y la ley natural. Esta coherencia entre ambos puede ser evidente o mediada por la razón; pero, en cualquier caso, se trata de un proceso puramente racional que rescata su formulación de todo riesgo relativista y reafirma la solidez de su sistema (lejos, por tanto, de la inclinación tomista).

Si la absoluta autonomía es imposible de salvar en la formulación de cualquier precepto — aunque sea de contenido moral—, Suárez garantiza un acceso autónomo en cuanto que es propiciado por la propia razón, pero al mismo tiempo compatible con la determinación divina, que ha dotado al ser humano de razón y le ordena atenerse a la ley natural accesible para ella.

Por tanto, solidez, equilibrio y una apasionada defensa de la libertad son algunas de las virtudes del planteamiento iusnaturalista de Francisco de Suárez, que sitúan su sistema como una de las reflexiones iusnaturalistas más acabadas y firmes de cuantas en el mundo han sido. En los esfuerzos actuales por recuperar el concepto de ley natural, la obra del doctor eximio sigue siendo, por tanto, visita obligada.

\section{BIBLIOGRAFÍA}

Aquino, T. (2001). Summa Theologiae. Madrid, BAC.

Aquino, T. (1953). Suma contra gentiles. Madrid, BAC. 
Baciero, F. (2007). «La ley moral natural según Francisco Suárez». Revista española de filosofía medieval, no 14 , pp. 105-118.

BRUST, S. J. (2012). «Retrieving a catholic tradition of subjective natural rights from the late sholastic Francisco Suarez, S.J.». Ave Maria Law Review, vol. 10/2, pp. 343-363.

Burgos, J. M. (2006). Para comprender a Jacques Maritain. Un ensayo histórico-crítico. Madrid: Fundación Emmanuel Mounier.

Carpintero, F. (2008). La ley natural, historia de un concepto controvertido. Madrid: Encuentro.

COMISIÓN TEOLÓGICA INTERNACIONAL (2009). A la recherche d'une éthique universelle: nouvelle regard sur la loi naturelle. Editrice vaticana.

Contreras, F. J. (2014). El sentido de la libertad. Historia y vigencia de la idea de ley natural. Barcelona: Stella Maris.

Denney, R. L. «The natural law foundation of virtue ethics», edición electrónica consultada en www.ignatiusinsight.com (San Francisco University) el 30 de mayo de 2013.

IRRAZÁBAL, G. (2011). «Ley natural y diálogo intercultural. Acerca del documento de la Comisión Teológica Internacional». Veritas, n 24, pp. 9-31.

McCauliff, C. M. A. (2009). "Cognition and Consensus in the Natural Law Tradition and in Neuroscience: Jacques Maritain and the Universal Declaration of Human Rights». Villanova Law Review, $\mathrm{n}^{\circ}$ 54, pp. 435-478.

Maritain, J. (1942). Les droits de l'homme et la loi naturelle, en Oeuvres complètes (1986), Friburgo (Suiza) - París, Saint Paul.

MaY, W. E. (1984). The Natural Law Doctrine of Francis Suarez. Washington DC: Catholic University of América.

Possenti, V. (2003). L'azione umana: morale, politica e Stato in Jacques Maritain. Roma: Città Nuova.

SuÁrez, F. (1971 y ss.). De legibus ac Deo legislatore. Madrid: CSIC, Instituto Francisco de Vitoria.

SuÁrez, F. (1965). Defensio Fidei. Corpus Hispanorum de Pace. Madrid: CSIC.

SuÁrez, F. Tratados morales. Trabajos preparatorios a edición. Coord: Senent De Frutos, J. A.

SweEt, W. (1998). «Persons, precepts and natural law». Études maritainiennes, no 14, pp. 141-165.

Viotтo, P. (2010). «Dalla cristianità istituzionalizzata alla città dell'uomo». Notes et documents, $\mathrm{n}^{\circ} 16$, pp. 25-38.

Wechsung, F. G. (2003). «La ley natural. Respuesta de Santo Tomás a una problemática actual». Congreso Tomista Internacional, Pontificia Accademia di San Tomasso, Roma.

WiLliams, D. (1998). «The inmutability of natural law according to Suarez». The thomist, $\mathrm{n}^{\mathrm{o}} 62$, pp. $97-115$.

Universidad Loyola Andalucía

Manuel López Casouete de Prado

Departamento de Filosofía y Humanidades

mlopez@uloyola.es

[Artículo aprobado para publicación en enero de 2018] 